Article

\title{
pH-Induced Association and Dissociation of Intermolecular Complexes Formed by Hydrogen Bonding between Diblock Copolymers
}

\author{
Masanobu Mizusaki ${ }^{1, *}$ (D), Tatsuya Endo ${ }^{1}$, Rina Nakahata ${ }^{1}$, Yotaro Morishima ${ }^{2}$ and \\ Shin-ichi Yusa 1,* \\ 1 Department of Applied Chemistry, Graduate School of Engineering, University of Hyogo, 2167 Shosha, \\ Himeji, Hyogo 671-2280, Japan; ta-endou@toyo-rubber.co.jp (T.E.); nkht9999@gmail.com (R.N.) \\ 2 Faculty of Engineering, Fukui University of Technology, 6-3-1 Gakuen, Fukui 910-8505, Japan; \\ morisima@fukui-ut.ac.jp \\ * Correspondence: mizusaki.masanobu@sharp.co.jp (M.M.); yusa@eng.u-hyogo.ac.jp (S.-i.-Y.); \\ Tel.: +81-79-267-4954 (S.-i.Y.)
}

Received: 26 July 2017; Accepted: 15 August 2017; Published: 17 August 2017

\begin{abstract}
Poly(sodium styrenesulfonate)-block-poly(acrylic acid) (PNaSS- $b$-PAA) and poly(sodium styrenesulfonate)-block-poly( $N$-isopropylacrylamide) (PNaSS- $b$-PNIPAM) were prepared via reversible addition-fragmentation chain transfer (RAFT) radical polymerization using a PNaSS-based macro-chain transfer agent. The molecular weight distributions $\left(M_{\mathrm{w}} / M_{\mathrm{n}}\right)$ of PNaSS- $b$-PAA and PNaSS- $b$-PNIPAM were 1.18 and 1.39 , respectively, suggesting that these polymers have controlled structures. When aqueous solutions of PNaSS-b-PAA and PNaSS- $b-$ PNIPAM were mixed under acidic conditions, water-soluble PNaSS- $b-\mathrm{PAA} / \mathrm{PNaSS}-b-\mathrm{PNIPAM}$ complexes were formed as a result of hydrogen bonding interactions between the pendant carboxylic acids in the PAA block and the pendant amide groups in the PNIPAM block. The complex was characterized by ${ }^{1} \mathrm{H} N M R$, dynamic light scattering, static light scattering, and transmission electron microscope measurements. The light scattering intensity of the complex depended on the mixing ratio of PNaSS- $b-\mathrm{PAA}$ and PNaSS- $b-P N I P A M$. When the molar ratio of the $N$-isopropylacrylamide (NIPAM) and acrylic acid (AA) units was near unity, the light scattering intensity reached a maximum, indicating stoichiometric complex formation. The complex dissociated at a $\mathrm{pH}$ higher than 4.0 because the hydrogen bonding interactions disappeared due to deprotonation of the pendant carboxylic acids in the PAA block.
\end{abstract}

Keywords: block copolymers; RAFT polymerization; complex; hydrogen bonding interactions; $\mathrm{pH}$-responsive

\section{Introduction}

Non-covalent interactions, such as hydrophobic [1], electrostatic [2,3], van der Waals [4], and hydrogen bonding interactions $[5,6]$, can be a driving force for the complex formation of polymers. In particular, hydrogen bonding interactions are an important driving force for the self-organization of natural polymers such as polysaccharides, proteins, and deoxyribonucleic acid (DNA).

It is known that hydrogen bonding interactions between amide groups or poly(ethylene glycol) (PEG) and carboxylic acid groups promote self-association or complex formation in water [7-9]. Shieh et al. [10] prepared a series of poly( $N$-isopropylacrylamide-random-acrylic acid) (P(NIPAM- $r$-AA)) copolymers and examined their glass transition behavior. They found that the incorporation of acrylic acid units into the PNIPAM polymer enhances the glass transition temperature $\left(T_{\mathrm{g}}\right)$ due to intermolecular hydrogen bonding between the pendant isopropyl amide groups and the carboxylic acid groups using ${ }^{1} \mathrm{H}$ NMR and Fourier-transform infrared analyses. As an example of such complex formation, 
Bian et al. [11] investigated the interaction between poly $(N, N$-diethylacrylamide) (PDEA), which is an analog of PNIPAM, and poly(acrylic acid) (PAA). The complex is formed between the two polymers through hydrogen bonding interactions with a stoichiometry of $r=0.6$ ( $r$ is the unit molar ratio of PAA/PDEA), and the complex formation depends on $\mathrm{pH}$ values. We lately reported [12] the complex formation behavior of poly(sodium stylenesulfonate)-block-PEG-block-poly(sodium stylenesulfonate) (PNaSS- $b-$ PEG- $b-$ PNaSS) with poly (methacrylic acid) (PMA). Both PNaSS- $b$-PEG- $b-$ PNaSS and PMA were synthesized via reversible addition-fragmentation chain transfer (RAFT) radical polymerization. Below $\mathrm{pH} 5$, water-soluble complexes were formed owing to the hydrogen bonding interactions between the PEG block in PNaSS- $b$-PEG- $b-\mathrm{PNaSS}$ and the carboxylic acids in PMA. The experimental data indicated that the PNaSS- $b-\mathrm{PEG}-b-\mathrm{PNaSS} / \mathrm{PMA}$ complex was spherical in shape. At $\mathrm{pH}$ greater than 5 , the complex dissociated because the hydrogen bonding interaction disappeared due to deprotonation of the pendant carboxylic acids in PMA.

In the present study, we focused on the complex formation behavior owing to the hydrogen bonding interactions as a function of the solution temperature instead of the solution $\mathrm{pH}$. Two species of diblock copolymers (Figure 1a), PNaSS-block-poly(acrylic acid) (PNaSS-b-PAA) and PNaSS-block-PNIPAM (PNaSS- $b-$ PNIPAM), were synthesized via RAFT radical polymerization [13]. The PNIPAM blocks of PNaSS- $b$-PNIPAM are also assumed to associate above the lower critical solution temperature (LCST) to form core-corona-type multi-polymer micelles [14]. When PNaSS- $b-\mathrm{PAA}$ and PNaSS- $b$-PNIPAM were mixed in a $0.1 \mathrm{M} \mathrm{NaCl}$ aqueous solution at $20{ }^{\circ} \mathrm{C}$, water-soluble PNaSS- $b$-PAA/PNaSS- $b$-PNIPAM complexes were formed through hydrogen bonding interactions between the PAA and PNIPAM blocks below pH 3.9 (Figure 1b). The complexes were maintained above the LCST of PNaSS- $b$-PNIPAM. The complexes dissociated under basic conditions when the hydrogen bonding interactions disappeared due to deprotonation of the pendant carboxylic acids in the PAA block.

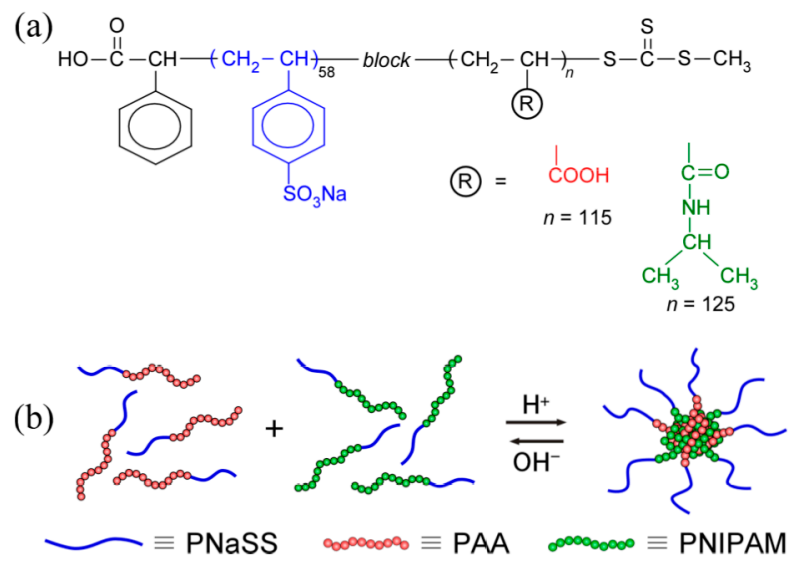

Figure 1. (a) Chemical structures of diblock copolymers used in this study: Poly(sodium styrenesulfonate $)_{58}$-block-poly(acrylic acid $)_{125}\left(\mathrm{PNaSS}_{58}-b-\mathrm{PAA}_{125}\right)$ and poly(sodium styrenesulfonate) ${ }_{58}{ }^{-}$ block-poly( $(N \text {-isopropylacrylamide })_{15}\left(\mathrm{PNaSS}_{58}-b-\mathrm{PNIPAM}_{115}\right)$, and (b) schematic representation of polymer chain mixing in the core and corona micelles comprising $\mathrm{PNaSS}_{58}-b-\mathrm{PAA}_{125}$ and $\mathrm{PNaSS}_{58}-b-\mathrm{PNIPAM}_{115}$.

\section{Experimental Section}

\subsection{Materials}

Acrylic acid (AA) from Kanto Chemical (Tokyo, Japan) was dried over $4 \AA$ molecular sieves and distilled under reduced pressure. N-isopropylacrylamide (NIPAM) from Aldrich (St. Louis, MO, USA) was purified by recrystallization from a mixed solvent of benzene and $n$-hexane. $\alpha$-Methyltrithiocarbonate-S-phenylaceticacid (MTPA) was synthesized as previously 
reported [15]. Sodium styrenesulfonate (NaSS) from Tokyo Chemical Industry (Tokyo, Japan) and $4,4^{\prime}$-azobis(4-cyanopentanoic acid) (V-501) from Aldrich were used as received. Methanol was dried using molecular sieves and distilled. Deionized water was used.

\subsection{Synthesis of PNaSS Macro-Chain Transfer Agent (PNaSS Macro-CTA)}

NaSS $(20.6 \mathrm{~g}, 100 \mathrm{mmol})$ and MTPA $(0.26 \mathrm{~g}, 1.0 \mathrm{mmol})$ were dissolved in $180 \mathrm{~mL}$ of water, and V-501 (5.6 mg, $0.2 \mathrm{mmol}$ ) was added to the aqueous solution. Polymerization was carried out at $70{ }^{\circ} \mathrm{C}$ for $3 \mathrm{~h}$ under Ar atmosphere. After the polymerization, the mixture was dialyzed against pure water for a week and recovered by a freeze-drying technique (yield $14.8 \mathrm{~g}$, number-average molecular weight $\left(M_{\mathrm{n}}\right)=1.22 \times 10^{4}$ (gel permeation chromatography (GPC)), molecular weight distribution $\left(M_{\mathrm{W}} / M_{\mathrm{n}}\right)=1.19$, and degree of polymerization $\left.(\mathrm{DP})=58\right)$. The obtained PNaSS could be used as a macro-CTA $\left(\mathrm{PNaSS}_{58}\right.$ macro-CTA).

\subsection{Preparation of $\mathrm{PNaSS}_{58}-b-P A A_{125}$}

AA $(0.86 \mathrm{~g}, 12 \mathrm{mmol})$ was dissolved in $15 \mathrm{~mL}$ of water, and PNaSS 58 macro-CTA (1.05 g, $0.087 \mathrm{mmol})$ and $\mathrm{V}-501(5.0 \mathrm{mg}, 0.018 \mathrm{mmol})$ were added to this solution. The mixture was deoxygenated by purging with Ar gas for $30 \mathrm{~min}$. Block copolymerization was carried out at $70{ }^{\circ} \mathrm{C}$ for $2 \mathrm{~h}$. The diblock copolymer was purified by dialysis against pure water for a week and then recovered using a freeze-drying technique. The diblock copolymer, $\mathrm{PNaSS}_{58}-b-\mathrm{PAA}_{125}$, was obtained (yield $1.79 \mathrm{~g}, M_{\mathrm{n}}=2.12 \times 10^{4}\left({ }^{1} \mathrm{H} \mathrm{NMR}\right), M_{\mathrm{w}} / M_{\mathrm{n}}=1.18$, and DP of the PAA block = 125).

\subsection{Preparation of $\mathrm{PNaSS}_{58}-b-\mathrm{PNIPAM} 115$}

$\operatorname{NIPAM}(2.26 \mathrm{~g}, 10.2 \mathrm{mmol})$ was dissolved in a mixed solvent of water and methanol (12.4 $\mathrm{mL}, 1 / 1$, $v / v)$, and PNaSS 58 macro-CTA $(0.96 \mathrm{~g}, 0.079 \mathrm{mmol})$ and V-501 $(4.6 \mathrm{mg}, 0.016 \mathrm{mmol})$ were added to this solution. The mixture was deoxygenated by purging with Ar gas for $30 \mathrm{~min}$. Block copolymerization was carried out at $60{ }^{\circ} \mathrm{C}$ for $5 \mathrm{~h}$. The diblock copolymer was purified by reprecipitation from a methanol solution into excess ether twice and then recovered using a freeze-drying technique. The diblock copolymer PNaSS $_{58}-b-$ PNIPAM $_{115}$ was obtained (yield $1.79 \mathrm{~g}, M_{\mathrm{n}}=2.52 \times 10^{4}\left({ }^{1} \mathrm{H} \mathrm{NMR}\right.$ ), $M_{\mathrm{w}} / M_{\mathrm{n}}=1.39$, and DP of the PNIPAM block $=115$ ).

\subsection{Preparation of the Water-Soluble Complex}

Stock solutions of $\mathrm{PNaSS}_{58}-b-\mathrm{PAA}_{125}$ and $\mathrm{PNaSS}_{58}-b-\mathrm{PNIPAM}_{115}$ were prepared by dissolving each polymer in $0.1 \mathrm{M} \mathrm{NaCl}$ aqueous solutions of $\mathrm{pH} 3$ and 10, respectively. To prepare the complex, the $\mathrm{PNaSS}_{58}-b-\mathrm{PNIPAM}_{115}$ aqueous solution was added to the $\mathrm{PNaSS}_{58}-b-\mathrm{PAA}_{125}$ aqueous solution over a period of five min, and the mixture was allowed to stand still for one day. The mixing ratio of the two diblock copolymers was adjusted based on the molar fraction of NIPAM units $\left(f_{\text {NIPAM }}=(\mathrm{NIPAM}) /((\mathrm{NIPAM})+(\mathrm{AA}))\right.$, where $(\mathrm{NIPAM})$ and $(\mathrm{AA})$ are the molar concentrations of NIPAM and AA units, respectively). The complex was prepared at $f_{\text {NIPAM }}=0.5$ unless otherwise noted.

\subsection{Measurements}

GPC measurements were performed with a Shodex 7.0 $\mu \mathrm{m}$ bead size GF-7F HQ column. A phosphate buffer at $\mathrm{pH} 9$, containing $10 \mathrm{vol} \%$ acetonitrile was used as an eluent at a flow rate of $0.6 \mathrm{~mL} / \mathrm{min}$ at $40^{\circ} \mathrm{C} . M_{\mathrm{n}}$ and $M_{\mathrm{w}} / M_{\mathrm{n}}$ were calibrated with standard PNaSS samples of 11 different molecular weights ranging from $1.37 \times 10^{3}$ to $2.61 \times 10^{6} .{ }^{1} \mathrm{H}$ NMR spectra were obtained with a Bruker DRX-500 spectrometer (Buick Rica, MA, USA) operating at $500 \mathrm{MHz}$. Light scattering measurements were performed using an Otsuka Electronics Photal DLS-7000DL equipped with a digital time correlator (ALV-5000E, Osaka, Japan). Sample solutions were filtered with a $0.2-\mu \mathrm{m}$ membrane filter. For dynamic light scattering (DLS) measurements, the data obtained were analyzed with ALV software version $3.0[16,17]$. For static light scattering (SLS) measurements, weight-average 
molecular weight $\left(M_{\mathrm{W}}\right)$, and radius of gyration $\left(R_{\mathrm{g}}\right)$ were estimated from Zimm plots [18]. Values of $d n / d C_{P}$ were determined with an Otsuka Electronics Photal DRM-1020 differential refractometer. Transmission electron microscopy (TEM) measurements were carried out using a JEOL JEM-2100 (Tokyo, Japan) at an accelerating voltage of $200 \mathrm{kV}$. The TEM sample was prepared by placing one droplet of the solution on a copper grid coated with Formvar. The sample was stained by sodium phosphotungstate and dried under reduced pressure. Percent transmittance $(\% T)$ measurements were performed using a JASCO V-630 BIO UV-Vis spectrometer (Tokyo, Japan) with a $10 \mathrm{~mm}$ path length quartz cell. The temperature was increased from 20 to $80^{\circ} \mathrm{C}$ with a heating rate of $1.0^{\circ} \mathrm{C} \cdot \mathrm{min}^{-1}$ using a JASCO ETC-717 thermostat system.

\section{Results and Discussion}

We prepared the diblock copolymers, $\mathrm{PNaSS}_{58}-b-\mathrm{PAA}_{125}$ and $\mathrm{PNaSS}_{58}-b-\mathrm{PNIPAM}_{115}$, via a RAFT technique using $\mathrm{PNaSS}_{58}$ macro-CTA. The DP of $\mathrm{PNaSS}_{58}$ macro-CTA, which was determined by GPC, was 58 (PNaSS 58 -macro-CTA). The DPs of the PAA and PNIPAM blocks were 125 and 115, respectively. These values were calculated from ${ }^{1} \mathrm{H}$ NMR peak area intensities derived from the PAA or PNIPAM block and an area derived from the PNaSS block. $M_{\mathrm{n}}$ and $M_{\mathrm{w}} / M_{\mathrm{n}}$ of the diblock copolymers were estimated from GPC. The results for the characteristics of the diblock copolymers are listed in Table 1 . The $M_{\mathrm{w}} / M_{\mathrm{n}}$ values are relatively small $\left(M_{\mathrm{w}} / M_{\mathrm{n}}<1.4\right)$, indicating that the controlled/living polymerizations proceeded successfully [13].

Table 1. Degrees of polymerization (DP) of PNaSS, PAA, and PNIPAM blocks, and number-average molecular weights $\left(M_{n}\right)$, and molecular weight distributions $\left(M_{W} / M_{n}\right)$ of the diblock copolymers.

\begin{tabular}{|c|c|c|c|c|c|c|c|}
\hline Samples & $\begin{array}{c}\text { DP of } \\
\text { PNaSS a }\end{array}$ & $\begin{array}{l}\text { DP of } \\
\text { PAA }^{b}\end{array}$ & $\begin{array}{c}\text { DP of } \\
\text { PNIPAM }^{b}\end{array}$ & $\begin{array}{c}M_{\mathrm{n}} \text { (theo) }^{\mathrm{c}} \\
\times 10^{-4}\end{array}$ & $\begin{array}{l}M_{\mathrm{n}}(\mathrm{NMR})^{\mathrm{b}} \\
\quad \times 10^{-4}\end{array}$ & $\begin{array}{c}M_{\mathrm{n}}(\mathrm{GPC})^{\mathrm{a}} \\
\quad \times 10^{-4}\end{array}$ & $M_{\mathrm{w}} / M_{\mathrm{n}}{ }^{\mathrm{a}}$ \\
\hline $\mathrm{PNaSS}_{58}-b-\mathrm{PAA}_{125}$ & 58 & 125 & & 2.07 & 2.12 & 3.51 & 1.18 \\
\hline PNaSS $_{58}-b-\mathrm{PNIPAM}_{115}$ & 58 & & 115 & 2.27 & 2.52 & 1.21 & 1.39 \\
\hline
\end{tabular}

${ }^{a}$ Estimated from gel permeation chromatography (GPC) eluted with a phosphate buffer solution at $\mathrm{pH} 9$ containing

10 vol \% acetonitrile; ${ }^{b}$ Estimated from ${ }^{1} \mathrm{H}$ NMR; ${ }^{c}$ Calculated from Equation (4).

When the polymerization is assumed an ideally living process, then the theoretical number-average molecular weight $\left(M_{\mathrm{n}}(\right.$ theo $\left.)\right)$ can be estimated as

$$
M_{\mathrm{n}}(\text { theo })=\frac{[\mathrm{M}]_{0} \quad x_{\mathrm{m}}}{[\mathrm{CTA}]_{0} 100} M_{\mathrm{m}}+M_{\mathrm{CTA}}
$$

where $[\mathrm{M}]_{0}$ is the initial monomer concentration, $[\mathrm{CTA}]_{0}$ is the initial $\mathrm{PNaSS}_{58}$ macro-CTA concentration, $x_{\mathrm{m}}$ is the conversion of the monomer, $M_{\mathrm{m}}$ is the molecular weight of the monomer, and $M_{\mathrm{CTA}}$ is the molecular weight of $\mathrm{PNaSS}_{58}$ macro-CTA. The $M_{\mathrm{n}}(\mathrm{NMR})$ values for $\mathrm{PNaSS}_{58}-b-\mathrm{PAA}_{125}$ and $\mathrm{PNaSS}_{58}-b-\mathrm{PNIPAM}_{115}$ were calculated from the ${ }^{1} \mathrm{H}$ NMR data. As shown in Table 1 , the $M_{\mathrm{n}}(\mathrm{NMR})$ values for $\mathrm{PNaSS}_{58}-b-\mathrm{PAA}_{125}$ and $\mathrm{PNaSS}_{58}-b-\mathrm{PNIPAM}_{115}$ were in reasonable agreement with the $M_{n}$ (theo) values. However, the $M_{n}$ (theo) and $M_{n}($ GPC) values for both diblock copolymers were found to be slightly different. This may be because the volume-to-mass ratio for PNaSS is different from those for $\mathrm{SS}_{58}-b-\mathrm{PAA}_{125}$ and $\mathrm{PNaSS}_{58}-b-\mathrm{PNIPAM}_{115}[19,20]$.

We attempted to monitor complex formation between $\mathrm{PNaSS}_{58}-b-\mathrm{PAA}_{125}$ and $\mathrm{PNaSS}_{58}-b-$ $\mathrm{PNIPAM}_{115}$ induced by the solution $\mathrm{pH}$ using ${ }^{1} \mathrm{H}$ NMR spectra measured in $\mathrm{D}_{2} \mathrm{O}$ containing $0.1 \mathrm{M}$ $\mathrm{NaCl}$ at pH 10 and 3. Figure 2 compares the ${ }^{1} \mathrm{H}$ NMR spectra of mixed solutions at $\mathrm{pH} 10$ and 3 . In Figure 2a, the resonance peaks at $1.16(f)$ and $3.91 \mathrm{ppm}(c)$ are attributed to the methyl and methine protons, respectively, in the pendant isopropyl group of the PNIPAM block are observed. Moreover, the resonance bands owing to the pendant phenyl protons in the PNaSS block are also detected at 6.1-7.9 ppm ( $a$ and $b$ ). The resonance bands in the 1.28-2.38 ppm region ( $d$ and $e$ ) are attributed to the sum of the main chain of the diblock copolymers. At pH 3, the intensities of the resonance peaks $f$ and 
$c$ derived from the PNIPAM block remarkably decreased, whereas those of $a$ and $b$ remained intact, as shown in Figure 2b. Besides this result, the resonance bands in the 1.28-2.38 ppm region ( $d$ and $e$ ) became broad. From the significant reduction of the motional freedom for the PNIPAM block at $\mathrm{pH} 3$, one can predict that the complexes are formed from $\mathrm{PNaSS}_{58}-b-\mathrm{PAA}_{125}$ and $\mathrm{PNaSS}_{58}-b-\mathrm{PNIPAM}_{115}$ owing to the hydrogen bonding interactions between the pendant carboxylic acids in the PAA block and the amide groups in the PNIPAM block. At pH 10, however, the complexes dissociated owing to the disappearance of the hydrogen bonding interactions as a result of deprotonation of the carboxylic acids in the PAA block.

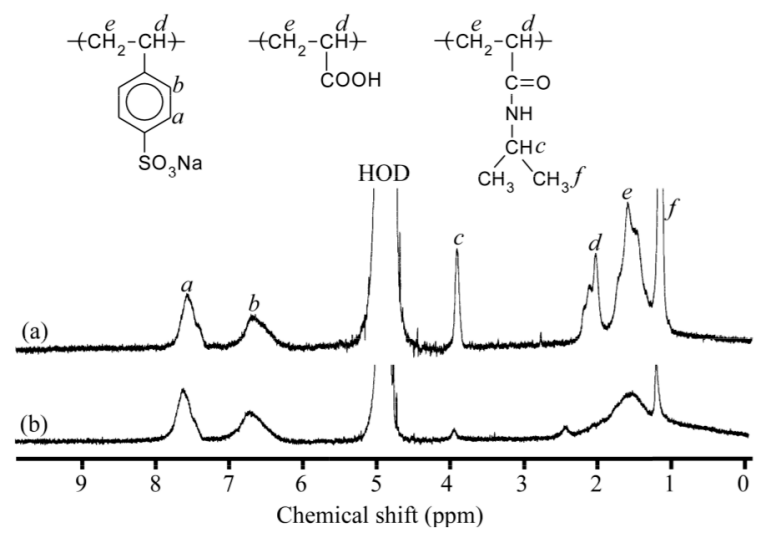

Figure 2. ${ }^{1} \mathrm{H}$ NMR spectra and peak assignment of the mixture of $\mathrm{PNaSS}_{58}-b-\mathrm{PAA}_{125}$ and PNaSS $_{58}-b-\mathrm{PNIPAM}_{115}$ in $\mathrm{D}_{2} \mathrm{O}$ containing $0.1 \mathrm{M} \mathrm{NaCl}$ at (a) $\mathrm{pH} 10$ and (b) $\mathrm{pH} 3$.

Figure 3 shows the light scattering intensities for a mixture of $\mathrm{PNaSS}_{58}-b-\mathrm{PAA}_{125}$ and $\mathrm{PNaSS}_{58}-b-\mathrm{PNIPAM}_{115}$ in $0.1 \mathrm{M} \mathrm{NaCl}$ at $\mathrm{pH} 3$ as a function of $f_{\text {NIPAM }}$. The total polymer concentration was kept constant at $4.4 \mathrm{~g} / \mathrm{L}$. An increase in the scattering intensity suggests an increase in the size of the complex. The maximum scattering intensity was observed at $f_{\text {NIPAM }}=0.5$. This result indicates that a stoichiometric interaction in the mixture of $\mathrm{PNaSS}_{58}-b-\mathrm{PAA}_{125}$ and $\mathrm{PNaSS}_{58}-b-\mathrm{PNIPAM}_{115}$ led to form a complex with largest aggregation number. The complex with $f_{\text {NIPAM }}=0.5$ was studied unless otherwise stated.

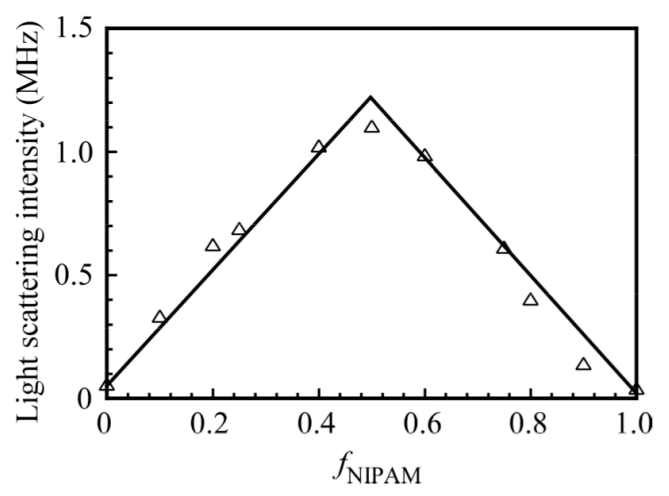

Figure 3. Light scattering intensities of the $\mathrm{PNaSS}_{58}-b-\mathrm{PAA}_{125} / \mathrm{PNaSS}_{58}-b-\mathrm{PNIPAM}_{115}$ complexes as a function of $f_{\text {NIPAM }}(=($ NIPAM $) /($ NIPAM $\left.)+(\mathrm{AA}))\right)$ in $0.1 \mathrm{M} \mathrm{NaCl}$ at $\mathrm{pH}$ 3. The total polymer concentration was fixed at $4.4 \mathrm{~g} / \mathrm{L}$.

Figure 4 shows the hydrodynamic radius $\left(R_{\mathrm{h}}\right)$ distributions for each diblock copolymer and the $\mathrm{PNaSS}_{58}-b-\mathrm{PAA}_{125} / \mathrm{PNaSS}_{58}-b-\mathrm{PNIPAM}_{115}$ complex at $\mathrm{pH} 3$ and 10 . The values of $R_{\mathrm{h}}$ were determined by DLS in $0.1 \mathrm{M} \mathrm{NaCl}$ and are indicated in the figure. The $R_{\mathrm{h}}$ values for $\mathrm{PNaSS}_{58}-b-\mathrm{PAA}_{125}$ and $\mathrm{PNaSS}_{58}-b-\mathrm{PNIPAM}_{115}$ were 3.5 and $3.7 \mathrm{~nm}$, respectively, which are reasonable 
for a unimer state. The $R_{\mathrm{h}}$ values of the complex at $\mathrm{pH} 3$ and 10 were 15.0 and $3.7 \mathrm{~nm}$, respectively. When $\mathrm{PNaSS}_{58}-b-\mathrm{PAA}_{125}$ and $\mathrm{PNaSS}_{58}-b-\mathrm{PNIPAM}_{115}$ were mixed at $\mathrm{pH} 3$, a water-soluble complex was formed due to hydrogen bonding interactions. On the other hand, at $\mathrm{pH} 10$ the complex dissociated because the hydrogen bonding interactions disappeared as a result of deprotonation of the pendant carboxylic acids.

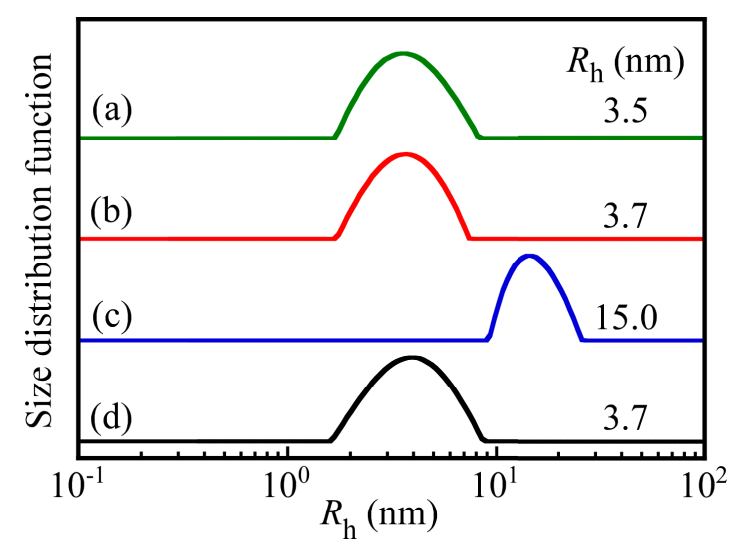

Figure 4. Hydrodynamic radius $\left(R_{\mathrm{h}}\right)$ distributions for (a) $\mathrm{PNaSS}_{58}-b-\mathrm{PAA}_{125}$ and (b) $\mathrm{PNaSS}_{58}-$ $b-\mathrm{PNIPAM}_{115}$ in $0.1 \mathrm{M} \mathrm{NaCl}$ at $\mathrm{pH} 3$, and the $\mathrm{PNaSS}_{58}-b-\mathrm{PAA}_{125} / \mathrm{PNaSS}_{58}-b-\mathrm{PNIPAM}_{115}$ complex at (c) $\mathrm{pH} 3$ and (d) $\mathrm{pH} 10$.

The relaxation rates $(\Gamma)$ measured at different scattering angles $(\theta)$ are plotted as a function of the square of the magnitude of the scattering vector $\left(q^{2}\right)$ for the mixture of $\mathrm{PNaSS}_{58}-b-\mathrm{PAA}_{125}$ and $\mathrm{PNaSS}_{58}-b-\mathrm{PNIPAM}_{115}$ in $0.1 \mathrm{M} \mathrm{NaCl}$ at $\mathrm{pH} 3$ in Figure 5. A linear plot passing through the origin suggests that the relaxation modes are virtually diffusive [21]. Thus, the $R_{\mathrm{h}}$ values can be estimated at a fixed $\theta$ of $90^{\circ}$ as the angular dependence is negligible.

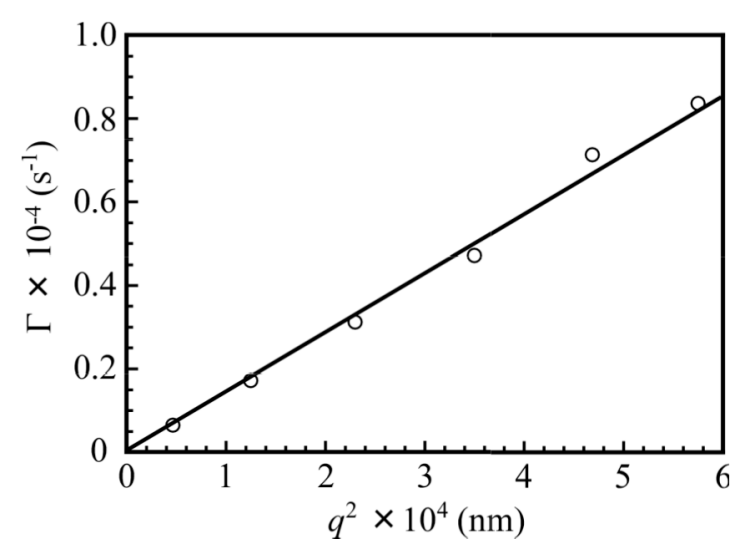

Figure 5. The relaxation rate $(\Gamma)$ plotted as a function of the square of the magnitude of the scattering vector $\left(q^{2}\right)$ for the $\mathrm{PNaSS}_{58}-b-\mathrm{PAA}_{125} / \mathrm{PNaSS}_{58}-b-\mathrm{PNIPAM}_{115}$ complex at $C_{\mathrm{p}}=4.4 \mathrm{~g} / \mathrm{L}$ in $0.1 \mathrm{M} \mathrm{NaCl}$ at $\mathrm{pH} 3$.

Figure 6 shows the light scattering intensities and $R_{\mathrm{h}}$ values for the mixture of $\mathrm{PNaSS}_{58}-b-\mathrm{PAA}_{125}$ and $\mathrm{PNaSS}_{58}-b-\mathrm{PNIPAM}_{115}$ in $0.1 \mathrm{M} \mathrm{NaCl}$ at $\mathrm{pH} 3$ as a function of the concentration of the mixture. In Figure $6 \mathrm{a}$, the scattering intensity increases sharply with increases in the concentration above a threshold of $0.9 \mathrm{~g} / \mathrm{L}$. Figure $6 \mathrm{~b}$ indicates that the $R_{\mathrm{h}}$ values for the complex are practically constant $\left(R_{\mathrm{h}}\right.$ is approximately $15 \mathrm{~nm}$ ) in the concentration range from 0.9 to $4.4 \mathrm{~g} / \mathrm{L}$. The results suggest that the formation of the complex between $\mathrm{PNaSS}_{58}-b-\mathrm{PAA}_{125}$ and $\mathrm{PNaSS}_{58}-b-\mathrm{PNIPAM}_{115}$ starts to occur 
above a critical concentration of $0.9 \mathrm{~g} / \mathrm{L}$. The apparent critical aggregate concentration $(\mathrm{CAC})$ value for the complex, estimated from the plots, is $0.9 \mathrm{~g} / \mathrm{L}$.

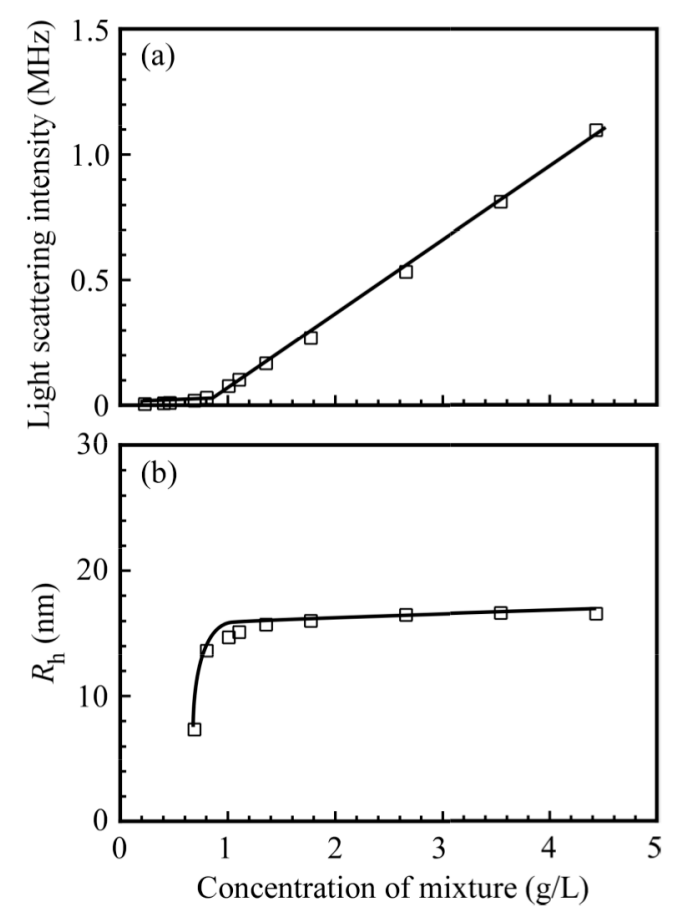

Figure 6. (a) Light scattering intensity and (b) hydrodynamic radius $\left(R_{\mathrm{h}}\right)$ of the $\mathrm{PNaSS}_{58}-b-$ $\mathrm{PAA}_{125} / \mathrm{PNaSS}_{58}-b-\mathrm{PNIPAM}_{115}$ complex as a function of the concentration of the mixture in 0.1 $\mathrm{M} \mathrm{NaCl}$ at $\mathrm{pH} 3$.

The apparent values of $M_{\mathrm{w}}$ and $R_{\mathrm{g}}$, determined by SLS measurements, are listed in Table 2. Figure 7 shows a Zimm plot for the $\mathrm{PNaSS}_{58}-b-\mathrm{PAA}_{125} / \mathrm{PNaSS}_{58}-b-\mathrm{PNIPAM}_{115}$ complex, which is formed from a mixture of $\mathrm{PNaSS}_{58}-b-\mathrm{PAA}_{125}$ and $\mathrm{PNaSS}_{58}-b-\mathrm{PNIPAM}_{115}$ in $0.1 \mathrm{M} \mathrm{NaCl}$ at $\mathrm{pH}$ 3. The aggregation number $\left(\mathrm{N}_{\mathrm{agg}}\right)$ was defined as the number of polymer chains forming one complex, which can be estimated from the $M_{\mathrm{W}}$ values of the complex and unimer. The result of this calculation gives an $N_{\text {agg }}$ of 46 for the complex. The chain numbers of $\mathrm{PNaSS}_{58}-b-\mathrm{PAA}_{125}$ and $\mathrm{PNaSS}_{58}-b-\mathrm{PNIPAM}_{115}$ for single complex are 22 and 24 , respectively, as calculated from $f_{\mathrm{NIPAM}}=0.5$ and the DP values of PAA and PNIPAM.

Table 2. Light scattering data for the $\mathrm{PNaSS}_{58}-b-\mathrm{PAA}_{125} / \mathrm{PNaSS}_{58}-b-\mathrm{PNIPAM}_{115}$ complex.

\begin{tabular}{cccccc}
\hline $\mathbf{p H}$ & $\boldsymbol{R}_{\mathbf{h}}{ }^{\mathbf{a}}(\mathbf{n m})$ & $\boldsymbol{M}_{\mathrm{w}}(\mathrm{SLS})^{\mathbf{b}} \times \mathbf{1 0}^{-\mathbf{5}}$ & $\boldsymbol{R}_{\mathrm{g}}{ }^{\mathbf{b}}(\mathbf{n m})$ & $\boldsymbol{R}_{\mathrm{g}} / \boldsymbol{R}_{\mathrm{h}}$ & $\boldsymbol{N}_{\text {agg }}{ }^{\mathrm{c}}$ \\
\hline 3 & 15.0 & 9.23 & 12.9 & 0.86 & 46 \\
10 & 3.7 & 0.20 & 13.6 & 3.7 & 1
\end{tabular}

a Estimated from dynamic light scattering (DLS); ${ }^{\mathrm{b}}$ Estimated from static light scattering (SLS); ${ }^{\mathrm{c}}$ Aggregation number calculated from $M_{\mathrm{w}}$ of the aggregate determined at $\mathrm{pH} 3$ and $M_{\mathrm{w}}$ of the corresponding unimer at $\mathrm{pH} 10$ determined from SLS. 


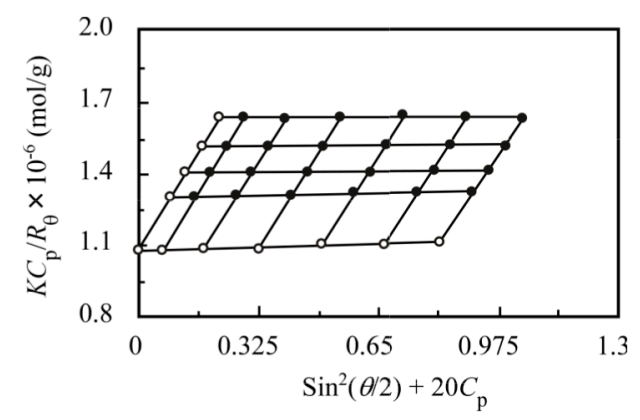

Figure 7. Zimm plot for the $\mathrm{PNaSS}_{58}-b-\mathrm{PAA}_{125} / \mathrm{PNaSS}_{58}-b-\mathrm{PNIPAM}_{115}$ complex with $f_{\mathrm{NIPAM}}=0.5$ in $0.1 \mathrm{M} \mathrm{NaCl}$ at $\mathrm{pH} 3$. Scattering angles $(\theta)$ range from $30^{\circ}$ to $130^{\circ}$ in $20^{\circ}$ increments.

The $R_{\mathrm{g}} / R_{\mathrm{h}}$ value indicates the shape of the molecular assemblies. The theoretical $R_{\mathrm{g}} / R_{\mathrm{h}}$ value of a homogeneous hard sphere is 0.778 but this value increases substantially for less dense structures and polydisperse mixtures; for example, $R_{\mathrm{g}} / R_{\mathrm{h}}=1.5-1.7$ for flexible linear chains in good solvents, whereas $R_{\mathrm{g}} / R_{\mathrm{h}} \geq 2$ for a rigid rod [22-24]. The $R_{\mathrm{g}} / R_{\mathrm{h}}$ ratio for the complex (Table 2 ) was 0.86 , suggesting that the shape of the complex may be spherical. The $R_{\mathrm{g}} / R_{\mathrm{h}}$ ratio for the unimer was 3.7, which indicates that the unimer was in a relatively expanded conformation with polydispersity.

To confirm the shape and size of the $\mathrm{PNaSS}_{58}-b-\mathrm{PAA}_{125} / \mathrm{PNaSS}_{58}-b-\mathrm{PNIPAM}_{115}$ complex at pH 3, TEM measurements were performed (Figure 8). The complex formed spherical objects with almost uniform contrast, suggesting that it comprises micelles with PAA/PNIPAM cores and PNaSS shells. The average radius estimated from the TEM images for the complex was $13.4 \mathrm{~nm}$, which is similar to the $R_{\mathrm{h}}$ value estimated from DLS.

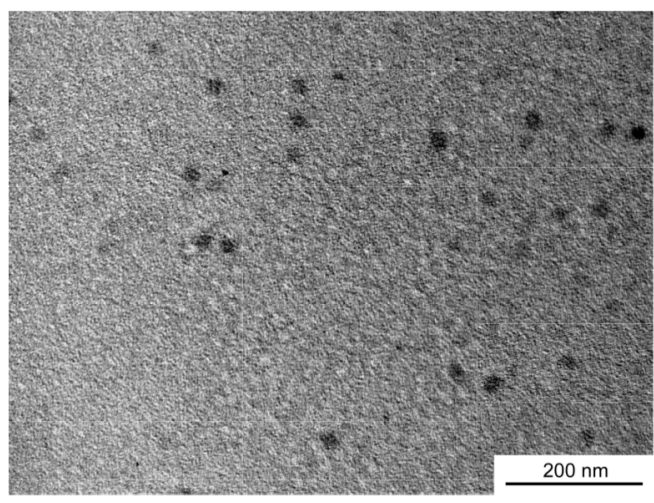

Figure 8. Transmission electron microscopy (TEM) image of the $\mathrm{PNaSS}_{58}-b-\mathrm{PAA}_{125}$ / $\mathrm{PNaSS}_{58}-b-\mathrm{PNIPAM}_{115}$ complex at $\mathrm{pH} 3$.

Figure 9a shows the light scattering intensities for the complex of $\mathrm{PNaSS}_{58}-b-\mathrm{PAA}_{125}$ and $\mathrm{PNaSS}_{58}-b-\mathrm{PNIPAM}_{115}$ in $0.1 \mathrm{M} \mathrm{NaCl}$ as a function of $\mathrm{pH}$. The light scattering intensity increased rapidly as the $\mathrm{pH}$ decreased from 4.0 to 3.5 , which suggests that the complex was formed below $\mathrm{pH} 3.5$. The light scattering intensity was nearly constant between $\mathrm{pH} 3.5$ and 2.5 suggests that $N_{\text {agg }}$ was constant in this $\mathrm{pH}$ region because the light scattering intensity is proportional to the molecular mass. Figure $9 \mathrm{~b}$ shows $R_{\mathrm{h}}$ values for the complex as a function of $\mathrm{pH}$. Above $\mathrm{pH} 4.0$, the $R_{\mathrm{h}}$ values were of the order of $3 \mathrm{~nm}$, suggesting that $\mathrm{PNaSS}_{58}-b-\mathrm{PAA}_{125}$ and $\mathrm{PNaSS}_{58}-b-\mathrm{PNIPAM}_{115}$ were in a unimer state. As the $\mathrm{pH}$ decreased, $R_{\mathrm{h}}$ started to increase at around $\mathrm{pH} 4.0$, reaching a maximum value of $15.0 \mathrm{~nm}$ at $\mathrm{pH}$ 3.5. As the $\mathrm{pH}$ continued to decrease, $R_{\mathrm{h}}$ was nearly constant between $\mathrm{pH} 3.5$ and 2.5, suggesting that not the aggregation number but the compactness of the complex was practically constant.

When the $\mathrm{pH}$ value was increased from 3 to 10 and subsequently decreased back to 3 , pH-induced $R_{\mathrm{h}}$ changes were found to be completely reversible. Figure 10 shows the $\mathrm{pH}$-induced changes of the 
$R_{\mathrm{h}}$ value of the $\mathrm{PNaSS}_{58}-b-\mathrm{PAA}_{125} / \mathrm{PNaSS}_{58}-b-\mathrm{PNIPAM}_{115}$ complex in $0.1 \mathrm{M} \mathrm{NaCl}$ cycled between $\mathrm{pH} 3$ and 10 with $20 \mathrm{~min}$ intervals. The changes in $R_{\mathrm{h}}$ between the two $\mathrm{pH}$ values were completely reproducible, indicating that the association and dissociation of the complex caused by $\mathrm{pH}$ changes was reversible over many cycles. This result suggests that the complex may find applications as a $\mathrm{pH}$-responsive controlled association-dissociation system.

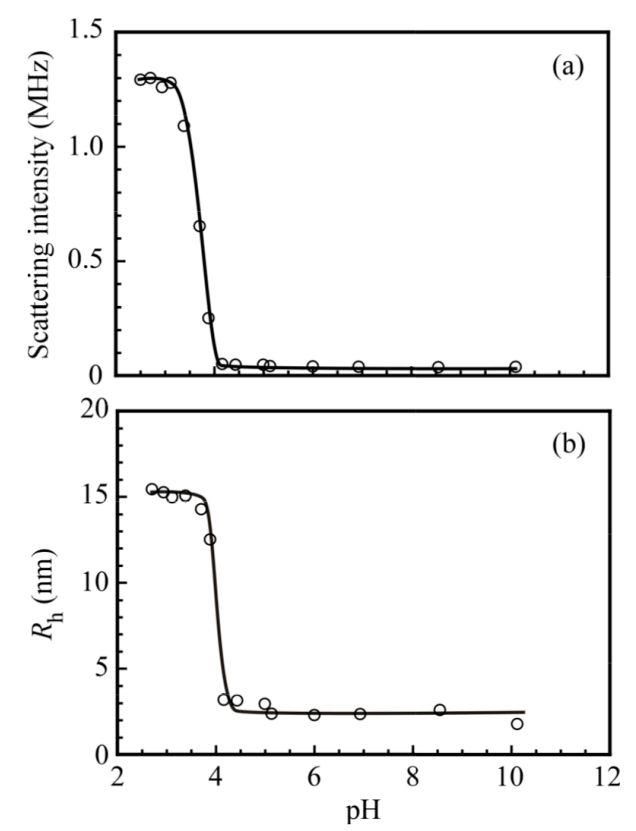

Figure 9. (a) Scattering intensity and (b) hydrodynamic radius $\left(R_{\mathrm{h}}\right)$ of the $\mathrm{PNaSS}_{58}-$ $b-\mathrm{PAA}_{125} / \mathrm{PNaSS}_{58}-b-\mathrm{PNIPAM}_{115}$ complex at $C_{\mathrm{p}}=4.4 \mathrm{~g} / \mathrm{L}$ in $0.1 \mathrm{M} \mathrm{NaCl}$ as a function of $\mathrm{pH}$.

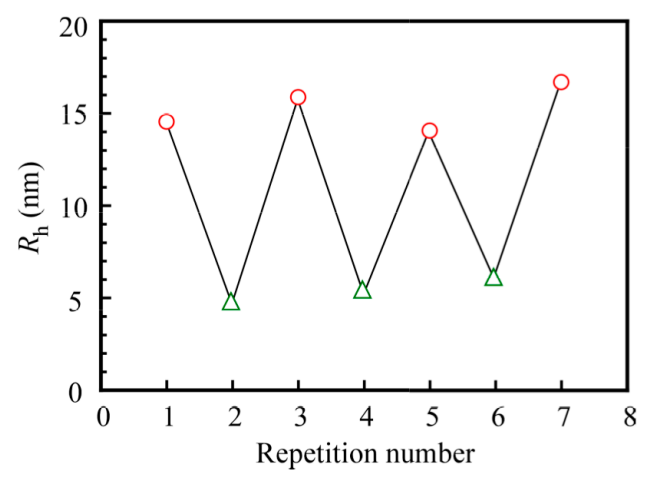

Figure 10. The hydrodynamic radius $\left(R_{\mathrm{h}}\right)$ of the $\mathrm{PNaSS}_{58}-b-\mathrm{PAA}_{125} / \mathrm{PNaSS}_{58}-b-\mathrm{PNIPAM}_{115}$ complex at $C_{\mathrm{p}}=4.4 \mathrm{~g} / \mathrm{L}$ in $0.1 \mathrm{M} \mathrm{NaCl}$ at $\mathrm{pH} 3(\bigcirc)$ and $\mathrm{pH} 10(\triangle)$.

To confirm the formation of the $\mathrm{PNaSS}_{58}-b-\mathrm{PAA}_{125} / \mathrm{PNaSS}_{58}-b-\mathrm{PNIPAM}_{115}$ complex via hydrogen bonding interactions, urea was added to the mixture of $\mathrm{PNaSS}_{58}-b-\mathrm{PAA}_{125}$ and $\mathrm{PNaSS}_{58}-b-$ PNIPAM $_{115}$ in $0.1 \mathrm{M} \mathrm{NaCl}$ at pH 3. It is known that urea disturbs hydrogen bonding interactions [25]. Figure 11 shows the light scattering intensity for the $\mathrm{PNaSS}_{58}-b-\mathrm{PAA}_{125} / \mathrm{PNaSS}_{58}-b-\mathrm{PNIPAM}_{115}$ complex as a function of the concentration of urea. The light scattering intensity decreased as the concentration of urea increased from 0 to $3.0 \mathrm{~mol} / \mathrm{L}$, and the scattering intensity dropped below $0.1 \mathrm{MHz}$ at $3.0 \mathrm{~mol} / \mathrm{L}$ urea concentration. These observations are indicative of the complete dissociation of the complex caused by an excess amount of urea. Thus, the complex was confirmed to be formed via hydrogen bonding interactions. 


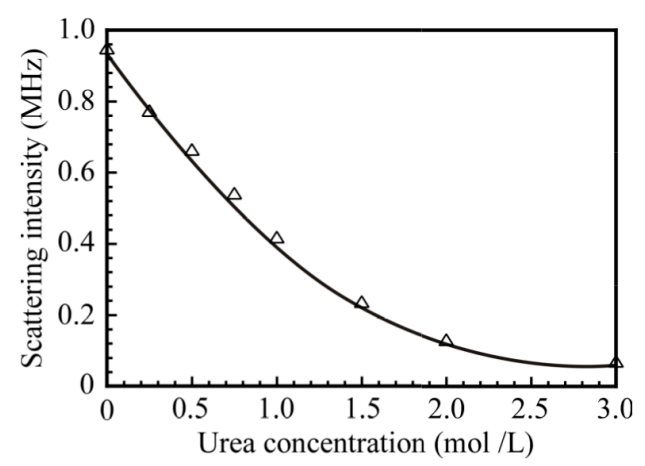

Figure 11. The scattering intensity of the $\mathrm{PNaSS}_{58}-b-\mathrm{PAA}_{125} / \mathrm{PNaSS}_{58}-b-\mathrm{PNIPAM}_{115}$ complex at $C_{\mathrm{p}}=4.4 \mathrm{~g} / \mathrm{L}$ in $0.1 \mathrm{M} \mathrm{NaCl}$ as a function of the urea concentration.

The NIPAM block in the PNaSS $_{58}-b-$ PNIPAM $_{115}$ diblock copolymer dissolves in water at room temperature, but it separates from aqueous solutions when heated above the lower critical solution temperature (LCST). Figure 12 shows the percent transmittance $(\% T)$ values monitored at $600 \mathrm{~nm}$ for $0.1 \mathrm{M} \mathrm{NaCl}$ aqueous solutions of $\mathrm{PNaSS}_{58}-b-\mathrm{PNIPAM}_{115}$ and a mixture of $\mathrm{PNaSS}_{58}-b-\mathrm{PAA}_{125}$ and $\mathrm{PNaSS}_{58}-b-\mathrm{PNIPAM}_{115}$ at $\mathrm{pH} 3$ and 10 , as a function of solution temperature. The diblock copolymer, $\mathrm{PNaSS}_{58}-b-\mathrm{PNIPAM}_{115}$, exhibited a significant $\% T$ change at $35-37^{\circ} \mathrm{C}$, which indicates the LCST. The mixture at $\mathrm{pH} 10$ also exhibited a slight $\% \mathrm{~T}$ change at $35-37^{\circ} \mathrm{C}$. On the other hand, the mixture at $\mathrm{pH} 3$ did not show any $\% \mathrm{~T}$ change in the temperature range from 20 to $80^{\circ} \mathrm{C}$. Ordinarily, the mechanism of LCST for PNIPAM can be explained as follows [26,27]. Below LCST, the PNIPAM chains are hydrated because the pendant amide groups form hydrogen bonding with water molecules, whereas above LCST, molecular motions prevail over the hydrogen bonding interactions resulting in the dehydration of the PNIPAM chains, thus leading to phase separation. Therefore, the PNIPAM chains dehydrated causing phase separation. In the case of the $\mathrm{PNaSS}_{58}-b-\mathrm{PAA}_{125} / \mathrm{PNaSS}_{58}-b-\mathrm{PNIPAM}_{115}$ complex at $\mathrm{pH} 3$, the pendant amide groups in the PNIPAM block interact with the pendant carboxylic acid in the PAA block irrespective of the temperature. Hence, the pendant amide groups in the PNIPAM block are prevented from forming hydrogen bonds with water molecules. Therefore, the LCST of the complex at $\mathrm{pH} 3$ cannot be observed. However, at $\mathrm{pH}$ 10, the mixture dissociated and hydrogen bonding interactions between the pendant amide groups in $\mathrm{PNaSS}_{58}-b-\mathrm{PNIPAM}_{115}$ and water molecules were formed at low temperature. Hence, the LCST can be observed for the mixture of $\mathrm{PNaSS}_{58}-b-\mathrm{PAA}_{125}$ and $\mathrm{PNaSS}_{58}-b-\mathrm{PNIPAM}_{115}$ at $\mathrm{pH} 10$, although the decrease in $\% T$ at the LCST was small comparing to the $\mathrm{PNaSS}_{58}-b-\mathrm{PNIPAM}_{115}$ case. This is simply because the concentration of the NIPAM units in the former solution is lower than that in the latter solution.

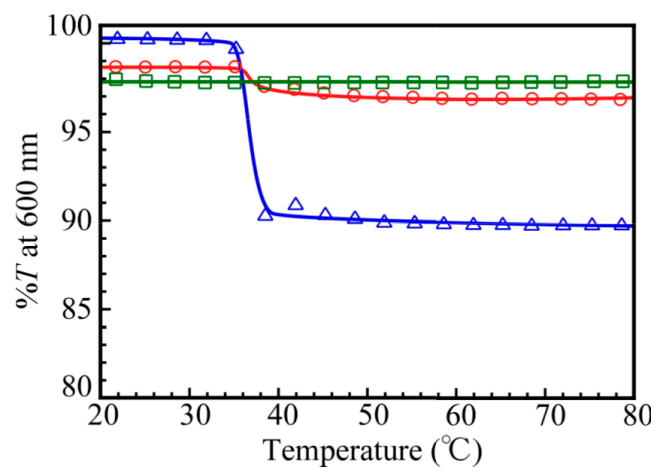

Figure 12. Percent transmittance $(\% T)$ at $600 \mathrm{~nm}$ for $0.1 \mathrm{M} \mathrm{NaCl}$ aqueous solutions of $\mathrm{PNaSS}_{58}-b-\mathrm{PNIPAM}_{115}(\triangle)$ and a mixture of $\mathrm{PNaSS}_{58}-b-\mathrm{PAA}_{125}$ and $\mathrm{PNaSS}_{58}-b-\mathrm{PNIPAM}_{115}$ at $\mathrm{pH} 3$ $(\square)$ and $\mathrm{pH} 10(\bigcirc)$ as a function of solution temperature. 


\section{Conclusions}

The diblock copolymers $\mathrm{PNaSS}_{58}-b-\mathrm{PAA}_{125}$ and $\mathrm{PNaSS}_{58}-b-\mathrm{PNIPAM}_{115}$ were prepared via RAFT-controlled radical polymerization using a $\mathrm{PNaSS}_{58}$ macro-CTA. Both polymerizations proceeded by a controlled mechanism. A mixture of $\mathrm{PNaSS}_{58}-b-\mathrm{PAA}_{125}$ and $\mathrm{PNaSS}_{58}-b-\mathrm{PNIPAM}_{115}$ formed a water-soluble complex under acidic conditions. The formation of the complex was confirmed by various measurement techniques. The ${ }^{1} \mathrm{H}$ NMR data indicated restricted motion of the PNIPAM block at $\mathrm{pH} 3$ in the complex owing to hydrogen bonding interactions between the pendant carboxylic acids in the PAA block and the pendant amide groups in the PNIPAM block. The DLS and SLS data suggested that the $\mathrm{PNaSS}_{58}-b-\mathrm{PAA}_{125} / \mathrm{PNaSS}_{58}-b-\mathrm{PNIPAM}_{115}$ complex was spherical in shape. When urea was added to the complex aqueous solution, the complex dissociated. This observation indicates that the driving force for the formation of the complex is hydrogen bonding interactions. The $\% \mathrm{~T}$ data indicated that the LCST of the complex was not observed at $\mathrm{pH} 3$, owing to the complex formation. However, the complex dissociated to a unimer above $\mathrm{pH} 4.0$.

Acknowledgments: This work was financially supported by a Grant-in-Aid for Scientific Research (17H03071 and 16K14008) from the Japan Society for the Promotion of Science (JSPS), JSPS Bilateral Joint Research Projects, and the Cooperative Research Program of "Network Joint Research Center for Materials and Devices (20174031)".

Author Contributions: Masanobu Mizusaki and Shin-ichi Yusa designed the specific experiments and were responsible for the writing ideas, experimental data analysis; Tatsuya Endo performed the specific experiments, samples preparation; Rina Nakahata TEM observations and data collection; Yotaro Morishima was responsible for the data analysis and manuscript's grammar proofreading.

Conflicts of Interest: The authors declare no conflict of interest.

\section{References}

1. Xu, R.; Winnik, M.A.; Riess, G.; Croucher, M.D. Micellization of polystylene-poly(ethylene oxide) block copolymers in water. 5. A test of the star and mean-field models. Macromolecules 1992, 25, 644-652. [CrossRef]

2. Harada, A.; Kataoka, K. Formation of polyion complex micelles in an aqueous milieu from a pair of oppositely-charged block copolymers with poly(ethylene glycol) segments. Macromolecules 1995, 28, 5294-5299. [CrossRef]

3. Kabanov, V.A.; Zezin, A.B.; Kasaikin, V.A.; Zakharova, J.A.; Litmanovich, E.A.; Ivleva, E.M. Self-assembly of ionic amphiphiles on polyelectrolyte chains. Polym. Int. 2003, 52, 1566-1572. [CrossRef]

4. Foreman, M.B.; Coffman, J.P.; Murcia, M.J.; Naumann, C.A.; Cesana, S.; Jordan, R.; Smith, G.S.; Naumann, C.A. Gelation of amphiphilic lipopolymers at the air-water interface: 2D analogue to 3D gelation of colloidal systems with grafted polymer chains. Langmuir 2003, 19, 326-332. [CrossRef]

5. Jeon, S.H.; Ree, T. Characterization of poly(carboxylic acid)/(poly(ethylene oxide) blends formed through hydrogen bonding by spectroscopic and calorimetric analyses. J. Polym. Sci. A 1999, 26, 1419-1428. [CrossRef]

6. Lee, W.; Chang, J.; Ju, S. Hydrogen-bond structure at the interfaces between water/poly(methyl methacrylate), water/poly(methacrylic acid), and water/poly(2-aminoethyl-methacrylate). Langmuir 2010, 26, 12640-12647. [CrossRef] [PubMed]

7. Abe, K.; Koide, M.; Tsuchida, E. Selective complexation of macromolecules. Macromolecules 1977, 10, 1259-1264. [CrossRef]

8. Velda, J.L.; Liu, Y.; Huglin, M.B. Effect of $\mathrm{pH}$ on the swelling behaviour of hydrogels based on $N$-isopropylacrylamide with acidic comonomers. Macromol. Chem. Phys. 1998, 199, 1127-1134. [CrossRef]

9. Erbil, C.; Akpinar, F.D.; Uyanik, N. Investigation of the thermal aggregation in aqueous poly $(N-$ isopropylacrylamide-co-itaconic acid) solutions. Macromol. Chem. Phys. 1999, 200, 2448-2453. [CrossRef]

10. Shieh, Y.-T.; Lin, P.-Y.; Chen, T.; Kuo, S.-W. Temperature, pH- and $\mathrm{CO}_{2}$-sensitive poly(N-isopropylacryl amide-co-acrylic acid) copolymers with high glass transition temperatures. Polymers 2016, 8, 434-449. [CrossRef]

11. Bian, F.; Liu, M. Complexation between poly(N,N-diethylacrylamide) and poly(acrylic acid) in aqueous solution. Euro. Polym. J. 2003, 39, 1867-1874. [CrossRef] 
12. Yokoyama, Y.; Yusa, S. Water-soluble complexes formed from hydrogen bonding interactions between a poly(ethylene glycol)-containing triblock copolymer and poly(methacrylic acid). Polym. J. 2013, 45, 985-992. [CrossRef]

13. Yusa, S.; Shimada, Y.; Mitsukami, Y.; Yamamoto, T.; Morishima, Y. pH-Responsive micellization of amphiphilic diblock copolymers synthesized via reversible addition-fragmentation chain transfer polymerization. Macromolecules 2003, 36, 4208-4215. [CrossRef]

14. Yusa, S.; Shimada, Y.; Mitsukami, Y.; Yamamoto, T.; Morishima, Y. Heat-induced association and dissociation behavior of amphiphilic diblock copolymers synthesized via reversible addition-fragmentation chain transfer radical polymerization. Macromolecules 2004, 37, 7507-7513. [CrossRef]

15. Yusa, S.; Endo, T.; Ito, M. Synthesis of thermo-responsive 4-arm star-shaped porphyrin-centered poly $(N, N$-diethylacrylamide) via reversible addition-fragmentation chain transfer radical polymerization. J. Poly. Sci. A 2009, 47, 6827-6838. [CrossRef]

16. Jakeš, J. Testing of the constrained regularization method of inverting Laplace transform on simulated very wide quasielastic light scattering autocorrelation functions. Czech. J. Phys. B 1988, 38, 1305-1316. [CrossRef]

17. Brown, W.; Nicolai, T.; Hvidt, S.; Stepanek, P. Relaxation time distributions of entangled polymer solutions from dynamic light scattering and dynamic mechanical measurements. Macromolecules 1990, 23, 357-359. [CrossRef]

18. Zimm, B.H. Apparatus and methods for measurement and interpretation of the angular variation of light scattering; preliminary results on polystyrene solutions. J. Chem. Phys. 1948, 16, 1099-1116. [CrossRef]

19. Yusa, S.; Fukuda, K.; Yamamoto, T.; Ishihara, K.; Morishima, Y. Synthesis of well-defined amphiphilic block copolymers having phospholipid polymer sequences as a novel biocompatible polymer micelle reagent. Biomacromolecules 2005, 6, 663-670. [CrossRef] [PubMed]

20. Yusa, S.; Konishi, Y.; Mitsukami, Y.; Yamamoto, T.; Morishima, Y. pH-responsive micellization of amine-containing cationic diblock copolymers prepared by reversible addition-fragmentation chain transfer (RAFT) radical polymerization. Polym. J. 2005, 37, 480-488. [CrossRef]

21. Xu, R.; Winnik, M.A.; Hallet, F.R.; Riess, G.; Croucher, M.D. Light-scattering study of the association behavior of styrene-ethylene oxide block copolymers in aqueous solution. Macromolecules 1991, 24, 87-93. [CrossRef]

22. Huber, K.; Bantle, S.; Lutz, P.; Burchard, W. Hydrodynamic and thermodynamic behavior of short-chain polystyrene in toluene and cyclohexane at $34.5^{\circ} \mathrm{C}$. Macromolecules 1985, 18, 1461-1467. [CrossRef]

23. Akcasu, A.Z.; Han, C.C. Molecular weight and temperature dependence of polymer dimensions in solution. Macromolecules 1979, 12, 276-280. [CrossRef]

24. Konishi, T.; Yoshizaki, T.; Yamakawa, H. On the "universal constants" $\rho$ and $\Phi$ of flexible polymers. Macromolecules 1991, 24, 5614-5622. [CrossRef]

25. Yin, X.; Stöver, H.D.H. Thermosensitive and $\mathrm{pH}$-sensitive polymers based on maleic anhydride copolymers. Macromolecules 2002, 35, 10178-10181. [CrossRef]

26. Heskins, M.; Guillet, J.E. Solution properties of poly(N-isopropylacrylamide). J. Macromol. Sci. A 1968, 2, 1441-1455. [CrossRef]

27. Winnik, F.M. Fluorescence studies of aqueous solutions of poly( $N$-isopropylacrylamide) below and above their LCST. Macromolecules 1990, 23, 233-242. [CrossRef]

(C) 2017 by the authors. Licensee MDPI, Basel, Switzerland. This article is an open access article distributed under the terms and conditions of the Creative Commons Attribution (CC BY) license (http://creativecommons.org/licenses/by/4.0/). 